\title{
O USO DO JORNAL PARA TRABALHAR COM A NOÇÃO DE FATO E TEMPO HISTÓRICO
}

Rivail Carvalho Rolim*

\section{RESUMO:}

Com este artigo estamos propondo uma forma de utilização do jornal impresso para trabalhar com as noções de fato e tempo histórico. Para isso fizemos uma discussão sobre a noção de duração social proposto por Fernand Braudel e, em seguida, demos alguns exemplos com notícias e reportagens de como essa metodologia poderá ser empregada no ensino fundamental e médio.

\section{PALAVRAS-CHAVES:}

evento; conjuntura; estrutura; tempo histórico; período histórico.

Uma das maiores dificuldades encontradas pelos professores que trabalham com alunos do nível fundamental e médio é o de abordar a noção de tempo histórico. Não se podia esperar algo diferente, tendo em vista que são conceitos utilizados no campo da história e que, por conseqüência, estão muito distantes do universo dos adolescentes. Elza Nadai e Circe Bittencourt enfatizam que "a noção de tempo, para quem se dedica a ensinar história nas escolas de $1^{0}$ e $2^{\circ}$ graus é uma das questões mais complexas e problemáticas" ${ }^{1}$. Essa é também a opinião de Maria Teresa Nidelcoff ao argumentar que, "se nas primeiras séries da escola de 1ํo grau a criança ainda tem dificuldade na percepção do tempo... que dizer, então, da

* Professor do Departamento de História UEM-PR e Doutorando em História Social UFF-RJ.

${ }^{1}$ NADAI, Elza ; BITTENCOURT, Circe M. F. Repensando a noção de tempo histórico no ensino. In: PINSKY, Jaime. (Org.) O ensino de história e a criação do fato. São Paulo: Contexto, 1991. p. 73. 
percepção do tempo histórico, que não se pode apreender através da experiência e cuja duração se torna de difícil compreensão para muitos adultos...! $!^{2}$ Além do mais, pesquisas vem demonstrando "que nossas idéias de tempo não são inatas nem automaticamente aprendidas, e sim construções intelectuais que resultam da experiência e da ação"3.

$\mathrm{Na}$ realidade, as crianças têm dificuldades em adquirir a noção de tempo, resolvendo isso gradualmente quando passam pelo processo de aprendizagem da linguagem. Contudo, só começam realmente a reconhecer seqüências temporais e, por conseqüência, ampliar sua capacidade de conceituação temporal com o desenvolvimento da memória. Quanto a isso, Whitrow argumenta que "o sentido da memória, na criança, envolve não apenas eventos de sua própria experiência mas, no devido tempo, outros da memória de seus pais e, por fim, da história do seu grupo social"4.

Os problemas, contudo, não param por aí, pois muita gente na atualidade acredita que o modo como medimos o tempo pelo calendário e o relógio é absoluto. Recentemente conversava com um colega que mora no Sul da Bahia sobre a reação de sua avó, quando lhe perguntavam as horas depois que foi introduzido o horário de verão no Brasil e ela respondia, se queriam saber no horário dos homens ou no horário de Deus. Situação similar é contada por Whitrow, quando o horário de verão foi adotado pela primeira vez no Reino Unido em 1916, ocasião em que muitos se opuseram, pois consideravam que o homem estava interferindo no que a famosa romancista Marie

${ }^{2}$ NIDELCOFF, Maria Teresa. A escola e a compreensão da realidade. São Paulo: Brasiliense, 1989. p. 81.

3 WHITTROW, G. J. O tempo na história. Rio de Janeiro: Jorge Zahar, 1993, p. 18.

${ }^{4}$ Idem. Ibidem. p. 18. 
Corelli chamou de "horário do próprio Deus ${ }^{5}$. Esta situação é bastante ilustrativa, no sentido de mostrar que muitos não entendem que há diferentes formas de medir o tempo, que há, por exemplo, civilizações que não medem o tempo em unidades como horas, minutos, dias, meses e anos. Em suma, é necessário que esteja claro que a noção de "tempo não se reduz a uma 'idéia' que surja do nada, por assim dizer, na cabeça dos indivíduos".

E se apontamos as dificuldades encontradas para compreender a noção de tempo, é necessário ficar claro que quando falamos de tempo histórico, estamos nos referindo a uma outra forma de estabelecer divisão, a uma outra concepção de orientação que procura organizar a sucessão dos acontecimentos nas sociedades. Portanto, é um conceito que deve ser trabalhado com o devido cuidado para que possa se tornar claro. Cabe salientar que, embora os professores das séries de alfabetização, desenvolvam algumas atividades, tais como mostrar aos alunos como vivem os homens que estão próximos a eles e de outros que são contemporâneos e vivem em outros lugares, bem como abordam a noção de geração, isto não é suficiente para que o conceito de tempo histórico seja compreendido. Um outro dado que deve ser lembrado é que o "estudo da história não tem sido explicitado tradicionalmente nos programas de integração social, (no qual) criou-se um estudo introdutório do social, baseado nos círculos concêntricos pelo qual as crianças estudam o tempo e o espaço mais próximos (a escola, a família, o bairro, a cidade), seguindo-se para o estado e finalmente para a nação"

Quando começamos a trabalhar com os alunos na adolescência, notamos que eles geralmente demonstram

${ }^{5}$ Idem. Ibidem. p. 15

${ }^{6}$ ELIAS, Norbert. Sobre o tempo. Rio de Janeiro: Jorge Zahar, 1998, p. 15

${ }^{7}$ NADAI, Elza ; BITTENCOURT, Circe M. F. Op. Cit. p. 74

História \& Ensino, Londrina, v. 8, p. 63-84, out. 2002 
possuírem noção do tempo cronológico, pois têm alguma consciência ou sensação de duração, na medida em que são capazes de mostrar as diferenças entre passado e presente, mas quando se trata de tempo histórico o conhecimento é bastante elementar e, às vezes, até inexistente. Geralmente quando mencionamos determinados fatos situados no passado, logo eles dizem que isso é do tempo do meu pai; que não tinham nascido; ou usam expressões "Ah professor! isso é do tempo da minha avó”. Pela experiência de vários anos trabalhando com esses alunos, poderíamos arriscar em dizer que falarmos em sociedades de tempos históricos situados a dois ou três mil anos atrás para alunos na adolescência é deveras incompreensível.

Todavia, precisamos enfrentar a tarefa de ensinarmos ou começarmos a trabalhar a história com os alunos e isso pressupõe lidarmos com o conceito relacionado ao tempo histórico. E quando falamos em tempo histórico estamos nos referindo justamente à delimitação dos fatos históricos situados ao longo da história das sociedades, ou seja, ao tempo de duração de uma determinada atividade produzida pelos sujeitos históricos, numa dada sociedade. É baseado nestes conceitos que falamos em "anos dourados", "anos de chumbo" e "anos rebeldes". Tais recortes ou denominações existem porque há a percepção de que certas etapas da vida social se diferenciam de outras. Neste caso devemos tomar um certo cuidado para não confundirmos a memória coletiva de grupos sociais com a história.

Nas séries iniciais, como geralmente se seguem os livros ou manuais didáticos, ao se tratar dos períodos históricos, se fala em Idade Antiga, Idade Média, Idade Moderna e Idade Contemporânea que foram consagrados pelo quadripartismo histórico. Na realidade este procedimento dos professores que trabalham no $1^{\mathrm{O}}$ e $2^{\mathrm{o}}$ graus é sintomático, pois nos cursos de graduação a divisão também é essa, legado do mimetismo do 
sistema universitário brasileiro que não se desvencilhou dos "nós" explicativos que a historiografia européia construiu e universalizou. Portanto, se no terceiro grau ocorre uma reprodução dessas periodizações, seria esperar muito se isto não acontecesse também no ensino de $1^{\circ}$ e $2^{2}$ graus, já que ambos os níveis de ensino insistem "no decalque e imitação de idéias alheias".

Quando os alunos se deparam com essa divisão, geralmente questionam porque se fala em idades na história. Nesse caso, se explica que são períodos situados ao longo do tempo que se diferenciam um do outro. Para ficar mais claro, mostramos que a forma de viver dos homens durante a antigüidade era distinta do período medieval, bem como do período moderno e contemporâneo; que a forma de trabalhar, a forma de morar e de se vestir se diferencia entre um período e outro.

Quando tratamos de Brasil, geralmente fazemos a divisão em Brasil-Colônia, Brasil-Império e Brasil-República. Nisso, explanamos que o período colonial se diferencia, entre outras coisas, do período imperial, porque o país era colônia de Portugal num momento e independente no outro. Quando se mostram as diferenças entre o Brasil-República e o BrasilImpério, geralmente mostramos que o país após sua independência dos lusitanos, continuou sendo uma Monarquia e, D. Pedro I, assumiu o trono no Brasil e só depois é que foi proclamada a República no Brasil.

Como podem notar, quando se fala das divisóes e se mostra porque um período se diferencia do outro se segue rigorosamente o que foi ensinado nos centros universitários

8 NEVES, Guilherme Pereira das. A catedral submersa ou a história no Brasil no terceiro milênio. Revista da SBPH n.13, Curitiba, 1997, p. 93-100. 
que, apesar de se proclamarem críticos, continuam reproduzindo as mesmas divisões e explicando as diferenças da mesma forma, quando a história se constituiu e se consolidou enquanto disciplina no Século XIX.

Fica evidente que o viés institucional ou os fatos que marcam os acontecimentos políticos continuam ainda definindo as periodizações e justificando as diferenças, apesar dos avanços da pesquisa histórica. Para constatarmos isso é só olharmos os cursos de história nos mais recônditos lugares desse país, que a divisão História Antiga, História Medieval, História Moderna e História Contemporânea, bem como Brasil-Colônia, BrasilImpério e Brasil-República continua quase intacta. Para fazermos referência somente ao início da contemporaneidade, momento este que já ocupou inúmeros debates, é provável que facilmente encontraremos docentes que vão dizer com todas as letras: "Eu sou professor de História Moderna" e começo trabalhando com a transição do feudalismo para o capitalismo. Aqui não importa se centra as atenções nos aspectos econômicos, culturais, sociais ou políticos. Uma coisa é certa, está arraigada a idéia de que mais ou menos nesse momento começa a Idade Moderna, por conseqüência, se inicia a partir daí. A impressão é de que muitos deles estão impregnados do espírito micheletiano, para o qual o século XVI, em sua grande e legítima extensão vai de Colombo a Galileu, da descoberta da terra à do céu.

Apesar dessa divisão já estar consagrada, ao ser estabelecida depois de longo período com o argumento de que era necessária para a explicação histórica, de que correspondeu a uma concepção geral do desenvolvimento e permitiu, entre outras coisas, mostrar as "características particulares de todo o período e pôr-se em plena luz o liame entre as diferentes formas de desenvolvimento histórico", dificilmente os alunos 
entendem o que seja fato ou o tempo histórico usando essa periodização como exemplo. Além do mais, essa concepção de história, que ainda carrega vários princípios do que se convencionou denominar de história tradicional ou factual, já foi muito criticada, na medida em que tinha a percepção de que a história diz respeito essencialmente à política e de que as atenções do historiador deveriam estar voltadas somente para os "grandes feitos" dos "grandes homens".

Contudo, a partir do momento que se constituiu uma concepção de história que começou a se interessar por toda a atividade, considerar que "tudo tem história" e todos os homens, independente da posição que ocupam na sociedade, de uma forma ou outra fazem parte do devir histórico, se abriu um leque de possibilidades para que os professores inovem na sua forma de trabalhar em sala de aula. Não só isso, mas o fato desta nova concepção de história trazer em seu bojo também uma "revolução documental", para usar uma expressão de Jacques Le Goff ${ }^{10}$, permite a utilização de diversos tipos de fontes no processo de ensino-aprendizagem, na medida em que todas as evidências históricas passaram a ser consideradas de igual importância, pois contém registros das atividades humanas.

Portanto, a partir dessas mudanças que se processaram com o advento da Escola dos Annales na década de 1930, passamos a considerar fato histórico tudo que é pensado ou produzido pelo homem, seja do ponto de vista material ou mental e independente da sua importância. Para citarmos aleatoriamente, são exemplos de fato histórico, a morte de Tancredo Neves e o impeachment de Collor, bem como o uso do chapéu pelos homens no Brasil no início do século, o uso da

9 GLENISSON, Jean. Iniciação aos estudos históricos. São Paulo: Difel, 1977, p. 52

${ }^{10}$ LE GOFF, Jacques. A história nova. São Paulo: Martins Fontes, 1993. 
famosa calça pantalona pelos jovens na década de setenta, a escravidão e o sistema colonial.

Além dessas mudanças na concepção de história, outras que dizem respeito ao tempo histórico também sofreram alterações. Os historiadores pertencentes à Escola dos Annales, como Marc Bloch e Lucien Febvre, mas principalmente Fernand Braudel ${ }^{11}$, procuraram evidenciar que existe uma multiplicidade de tempos na história e não somente o tempo breve, o acontecimento, como entendia a história tradicional ou factual propugnada por Langlois e Seignobos.

Para Fernand Braudel, em artigo escrito na década de cinqüenta, para a compreensão de realidades históricas a idéia de duração social é fundamental, na medida em que os fatos históricos têm variações diferenciadas, pois existem aqueles que têm um momento preciso, outros que cumprem um determinado ciclo, por fim há também aqueles resistentes, duros de morrer ou acabar ${ }^{12}$. Portanto, para Fernand Braudel temos um fato histórico breve e curto - o evento -, um outro que decompõe o passado em fatias - a conjuntura - e um último que se mantém, permanece, sobrevive apesar do tempo - é a estrutura ou longa duração. Todavia, é bom que se destaque, que esses tempos dos fatos históricos não estão isolados, na realidade, há um entrecruzamento desses movimentos, com interações e rupturas. Como não são independentes, acontecimentos podem estar ligados a uma conjuntura, que por sua vez se liga às estruturas ou longa duração.

Para usarmos as palavras do autor, o evento é explosivo, "novidade sonante", com sua "fumaça excessiva, enche a consciência dos contemporâneos, mas não dura, vê-se apenas

${ }^{11}$ BRAUDEL, Fernand. Escritos sobre a história. São Paulo: Perspectiva, 1992, p. 41.

${ }^{12}$ Idem. Ibidem. p. 50,51 
sua chama". Mas Braudel chama a atenção que o evento, pode conter uma série de significações, revelar movimentos muitos profundos, que uma hora ou outra explodem ${ }^{13}$. O acontecimento ou evento é como se fosse a ponta de um iceberg, todavia, esses fatos miúdos, uns brilhantes outros obscuros não formam toda a realidade, toda a espessura da história.

Se existem os momentos explosivos que delimitam, há períodos que os contemporâneos ficam com a impressão de que estão passando por um turbilhão, de que a história parece se acelerar em função de quão profundas podem ser as mudanças que ocorrem ao longo de dez ou vinte anos. Na realidade, às pessoas ou os grupos têm consciência de terem vivido períodos da vida social que se diferenciaram dos outros. Nesse caso, estamos nos referindo à conjuntura que, segundo Fernand Braudel, é composto de um ciclo, até mesmo de um interciclo, que propõe a nossa escolha uma dezena de anos, um quarto de século e, no limite extremo, meio século ${ }^{14}$.

Por último, devemos ressaltar que há aspectos da realidade social que parecem ficar intocados ao longo de uma infinidade de gerações. Por mais que os anos passem, que aconteça ao redor mil rupturas e agitações, mantém a coerência e a fixidez. Aliás dá a impressão que ganharam estabilidade, que são imutáveis. Nesse caso, estamos justamente nos referindo à longa duração, a estrutura, que são fatos históricos que atravessam sociedades e séculos e escapam a percepção dos contemporâneos. Para exemplificarmos, a escravidão no Brasil, que durou quase quatro séculos e o cristianismo ocidental, com mais de dois mil anos.

Fizemos essa discussão sobre fato e tempo histórico, que se referem justamente à duração social, pois nos parece difícil

\footnotetext{
${ }^{13}$ Idem. Ibidem. p. 45.

${ }^{14}$ Idem. Ibidem. p. 47.
} 
trabalhar com história sem o uso desses conceitos. Podemos até ser criativos nas aulas, usando fotografias, filmes, músicas, poesias e obras literárias ou tudo que se convencionou chamar de "novas linguagens", contudo, "todo o cuidado com a incorporação das 'novas linguagem' é pouco, principalmente numa época de desvalorização do conteúdo socialmente acumulado pelo conhecimento científico" ${ }^{15}$. Diante desses problemas é fundamental definir a metodologia que diz respeito ao campo do historiador para empreendermoś qualquer atividade de reflexão histórica. Se não fazemos isso, corremos o risco de tratarmos os fatos históricos de uma realidade social ou outra como se fossem coisas pitorescas. Talvez o fato de não se estar dando a devida atenção ao trabalho com esses conceitos é que nos deparamos nas ruas com alunos dizendo: "Olha como eles iam ao banheiro na Idade Média"; "Nossa, eles acreditavam em bruxas"; "Não acredito que os deuses deles chamavam Zeus ou Prometeu"; "Os artesãos não tinham dó de matar gatos no século XVIII".

Devemos registrar que, apesar das críticas em relação ao trabalho de Braudel, sugerimos essa periodização proposta por um dos principais historiadores franceses, pois consideramos que no $1^{\circ}$ e $2^{\circ}$ graus a compreensão desses conceitos é fundamental para que o aluno vá compreendendo o que é história, além do que, é bastante didática e podemos aplicá-la a diferentes realidades históricas com o uso de diversos materiais ${ }^{16}$. Seguindo as sugestões de Braudel, estamos propondo que, ao invés de se tentar explicar o que é fato e tempo histórico

${ }^{15}$ NAPOLITANO, Marcos. A televisão como documento. In: BITENCOURT, Circe. O saber histórico na sala de aula. São Paulo: Contexto, 1997. p. 149 ${ }^{16}$ Ressaltamos que em outros níveis de ensino essa divisão braudeliana pode ser problematizada, pois o nível de interpretação dos alunos sobre os processos históricos permite um trabalho mais aprofundado sobre a duração social. 
usando os exemplos que estão nos livros e manuais didáticos muitas vezes, ainda organizados de uma forma tradicional recorreríamos ao material recolhido pelo professor ou pelos próprios alunos.

Neste caso, o jornal impresso, além de ser um material prático e adequado, é uma fonte que traz uma gama variada de registros sob os mais diferentes âmbitos da sociedade, tanto nas reportagens como nas notícias, portanto, se enquadra numa concepção de história que contempla inúmeros temas, diferentes abordagens e múltiplos objetos. $\mathrm{O}$ uso do jornal em sala de aula pode também desenvolver uma atividade de valorização da leitura e da escrita, bem como de aprofundamento do domínio da língua, que ultimamente vem sendo substituída por meios audiovisuais que garantem acesso a informação, mas coloca em segundo plano a prática da leitura. Diante dessa situação é que Ciro F. Cardoso com um certo pesar destaca que "agora, inteiramente defasada, a escola não consegue responder aos desafios e competições do século XX tardio, de modo a preservar nos alunos os níveis de atenção e interesse que permitam treiná-los a que leiam, desenvolvam a leitura como atividade habitual" ${ }^{17}$. Para esse autor, o fato de existirem correntes que argumentam que não há formas erradas de falar ou escrever, e sim, registros diferentes do uso da língua, de certa forma é uma confissão disfarçada de impotência ou derrota da escola tradicional ${ }^{18}$.

Quanto ao uso do jornal nas aulas de história, na realidade desde a invenção da imprensa no século $\mathrm{XV}$, esse veículo de informação vem ganhando amplos espaços para registrar as atividades do homem. Todavia, com a consolidação

${ }^{17}$ CARDOSO, Ciro Flamarion. No limiar do século XXI. Tempo, v.1, n. 2, Rio de Janeiro, 1996, p. 9.

${ }^{18}$ CARDOSO, Ciro Flamarion. Ibidem. p. 9. 
da história tradicional no final do oitocentos, que exigia do historiador uma rigorosa crítica dos documentos, implicando, sobretudo, em verificar se ele era falso ou verdadeiro, as fontes não oficiais ficaram sob suspeição. Os periódicos, por exemplo, ficaram sob desconfiança, tendo em vista que se considerava que as informações contidas no editorial, nas reportagens ou mesmo nas notícias não eram marcadas pela objetividade tal qual um documento emitido por uma autoridade.

Com o avanço das pesquisas históricas, verificou-se que não há documento-verdade, pois todos são resultados de montagens conscientes ou inconscientes das sociedades responsáveis pela sua produção. $\mathrm{O}$ esquecimento de uma fonte ou não é resultado das relações de forças conflitantes e do empenho dos agentes sociais envolvidos que pretendem impor ao futuro uma determinada imagem da sociedade ${ }^{19}$. Com todas essas críticas a idéia de um documento verdadeiro desaparece, na realidade passamos a considerar que todos os documentos são, ao mesmo tempo falsos e verdadeiros, pois foram construídos por agentes sociais sob determinadas condições ${ }^{20}$. Com isso não estamos querendo dizer que não precisamos empreender uma crítica rigorosa sobre a fonte, aliás, o trabalho de análise documental se torna mais difícil à medida que todos são possíveis de serem usados pelo historiador.

Vencido essa etapa na qual os pesquisadores mostraram como poderíamos usar diversos tipos de fontes para analisar as sociedades, os jornais passaram a ser considerados documentos importantes para as pesquisas históricas, tendo em vista que encontramos dados sobre a sociedade, seus usos e costumes, informes sobre questões econômicas e políticas, a vida de

${ }^{19}$ CAPElATO, Maria H. Rolim. Imprensa e história do Brasil. São Paulo: Contexto, 1988. P. 24.

${ }^{20}$ Idem. Ibidem. p. 24. 
pessoas "ilustres" e também de sujeitos anônimos. Em suma, a imprensa registra os fatos mais diversos, por isso é uma verdadeira mina de informação ${ }^{21}$. Todavia, não podemos perder de vista que a produção de um jornal "pressupõe um ato de poder no qual estão implícitas relações a serem desvendadas", mais ainda, seus "produtores engendram imagens da sociedade que serão reproduzidas em outras épocas"22.

No Brasil, com a vinda da família real, ao lado da imprensa régia, surgem os primeiros jornais em diversas províncias, sobressaindo a imprensa de oposição política no movimento de independência. Com isso destacam-se Correio Braziliense de José Hypolito da Costa, Revérbero Constitucional Fluminense escrito por Joaquim Gonçalves Ledo, Correio do Rio de Janeiro de João Soares Lisboa e Typhis Pernambucano fundado e dirigido por Frei Caneca. Para conter às críticas feitas a Coroa portuguesa, o governo imperial desencadeou uma severa censura, que chegou a impedir a circulação de jornais. Segundo Maria H. Rolim Capelato o "Correio Braziliense tornou-se famoso não só pelas críticas ao governo mas principalmente porque foi publicado em Londres devido ao seu impedimento no Brasil"23.

No contexto da Proclamação da República e fim da escravidão a imprensa também estava presente, noticiando os fatos. Jornais como O Correio Paulistano, A Província de São Paulo que depois modificou o nome para O Estado de São Paulo e o Diário Popular trouxeram várias informações sobre as mudanças que estavam acontecendo no país. O Jornal do Comércio fundado em 1827, por exemplo, trazia a seguinte notícia em 13/05/1888:

\footnotetext{
${ }^{21}$ Idem. Ibidem. p. 20, 21.

22 Idem. Ibidem. p. 25.

${ }^{23}$ Idem. Ibidem. p. 38.
} 
Estava o céu encoberto de escuros nimbos: mas da banda do ocidente entrou a corar-se, com tênue faixa esbranquecida, e logo depois era púrpura o ouro, magnífico dossel de astro-rei, que lentamente emergiu no extremo do horizonte não ocupado pelo acúmulo de negrumes [...] Viu-se enfim a aurora redentora dos cativos $^{24}$.

Com a urbanização ocorrida no início do século XX, vários jornais foram sendo criados para atender a demanda de um segmento social letrado. Assim, o Jornal do Brasil foi criado em 1891, o Correio da Manhã em 1901, O Globo em 1925, o Diário Carioca em 1928 e o Diário de Notícias em 1930. Nesta breve explanação não poderíamos deixar de mencionar os jornais a Tribuna da Imprensa criado em 1949 e Última Hora em 1951, que marcaram época devido a introdução de novas técnicas de apresentação gráfica e inovações na cobertura jornalística, renovando a linguagem da imprensa ${ }^{25}$.

$\mathrm{Na}$ atualidade temos periódicos como o Jornal do Brasil, Folha de São Paulo, O Estado de São Paulo e o Globo, que estiveram presentes em vários momentos da história da República e continuam sendo ainda importantes veículos de informação escrita no país. Contudo, a denominada grande imprensa concorre com inúmeros jornais regionais e locais na tarefa de noticiar os acontecimentos do país e até mesmo do exterior. Os periódicos dos centros regionais não tem uma divulgação nacional, mas trazem importantes informações sobre a realidade histórica dos grupos sociais residentes nesses locais, bem como a relação que estabelecem com outros territórios do país. Esses jornais podem inclusive noticiar aspectos da

${ }^{24}$ APUD CAPELATO, Maria H. Rolim. Op. Cit. p. 42

${ }^{25}$ ABREU, Alzira A. Os suplementos literários: os intelectuais e a imprensa nos anos 50. In (Org.) A imprensa em transição: o jornalismo brasileiro nos anos 50. Rio de Janeiro: FGV, 1996, p. 15. 
realidade social que a grande imprensa não se preocupa em divulgar. Nesse sentido, constituem uma fonte privilegiada para o trabalho que estamos propondo.

Antes de iniciarmos propriamente o trabalho que estamos sugerindo temos de salientar que as informações contidas nos jornais estão nas reportagens e nas notícias, seja sobre cultura, política ou economia. Neste caso é fundamental entender o que é notícia e o que é reportagem, pois são os elementos do jornal que será utilizado para trabalharmos com a noção de fato e tempo histórico.

Por notícia entendemos a descrição de um fato de uma forma clara e objetiva. Em outras palavras, na notícia geralmente o jornalista constrói um texto mais isento e sintético, que transmite a informação, o fato de modo mais direto, enfim, estabelece uma relação quase que imediata entre a fonte e o receptor da notícia. A notícia poderia ser percebida, pela presença de um texto organizado com base no pressuposto de que todas as informações essenciais a respeito do acontecimento estão dadas. Recorrendo a Roland Barthes, poderíamos afirmar que a notícia contém uma informação total, contém em si todo o seu saber, não é preciso conhecer nada do mundo para entender o conteúdo de uma notícia. Em suma, é uma estrutura fechada ${ }^{26}$.

A reportagem difere da notícia por vários aspectos. $\mathrm{O}$ primeiro é que a reportagem não trata de informar um fato ou uma série de fatos, mas um assunto conforme um ângulo preestabelecido. Para exemplificar, noticia-se que um governo foi deposto e que ocorreu um assalto; fazem-se reportagens sobre crise política, econômica e social, sobre as condições de vida da população, mudanças na forma de habitar, de se vestir

${ }^{26}$ BARTHES, Roland. Estrutura da notícia. In: Crítica e verdade. São Paulo: Perspectiva, 1970 , p. 58/59. 
e de se alimentar. Há reportagens em que predomina a investigação e o levantamento de dados, já em outras, o jornalista chega a fazer uma interpretação. Segundo Nilson Lage de "qualquer maneira, existe sempre alguma interpretação nas reportagens. O importante é que se respeitem os fatos, dos quais não se pode discordar, e se dê ao leitor, com humildade, o direito de avaliá-los segundo seu próprio repertório, seus valores" ${ }^{\prime 2}$.

Depois dessas considerações, procuraremos analisar algumas notícias e reportagens coletadas nos jornais, objetivando mostrar como podemos trabalhar a noção de fato e tempo histórico, com suas variáveis de duração. Gostaríamos de ressaltar que não estamos com isso propondo que todos os conteúdos constantes nos currículos escolares sejam abordados somente com fontes de uma maneira geral ou com jornal. $\mathrm{Ou}$ seja, não estamos com a "febre" de acreditar que somente trabalhando com documentos é possível analisar as realidades históricas ou de que o trabalho de análise desse material em sala de aula no ensino fundamental é suficiente para tratarmos os conteúdos históricos de diferentes sociedades em múltiplas temporalidades. Em outras palavras, estamos afirmando que o material didático e mesmo o conhecimento histórico acumulado não pode ser ignorado no preparo das aulas. Na realidade, se usarmos única e exclusivamente as fontes para análise das realidades históricas, cairemos num empirismo grosseiro.

O Jornal do Brasil de 04 de maio de 2002, na parte internacional, tem uma matéria com o título: "Bomba mata 60 civis na Colômbia". A notícia se refere a explosão de uma bomba numa determinada região da Colômbia, matando em torno de 60 pessoas e deixando outras 93 feridas. $\mathrm{O}$ atentado ocorreu à

${ }^{27}$ LAGE, Nilson. Estrutura da notícia. São Paulo: Ática, 1987, p. 48 
noite a $600 \mathrm{~km}$ da capital Bogotá, quando guerrilheiros das FARC (Forças Armadas Revolucionárias da Colômbia) lançaram um artefato explosivo, provavelmente feito com um botijão de gás acoplado a bananas de dinamite na praça principal da cidade.

Fica claro que estamos tratando de um fato histórico, pois num determinado dia e num determinado local houve uma explosão de uma bomba que matou dezenas de pessoas e feriu outras. Portanto, não há como negar que isso aconteceu, logo não é um evento semiológico. O tempo histórico está situado no plano do acontecimento, pois não durou mais do que um dia, ou seja, rapidamente acabou. Todavia, esse acontecimento pode conter uma série de significações, ser conseqüência de aspectos mais profundos da sociedade colombiana e que, a explosão da bomba simplesmente representou a ponta do iceberg. Esse evento tem ligações com aspectos conjunturais que a Colômbia está atravessando, na medida em que nos últimos anos o governo adotou uma política de repressão aos grupos guerrilheiros e em retaliação os membros das FARC têm feito uma série de atentados terroristas. Ou seja, é evidente que a explosão da bomba em si não explica toda a realidade que a sociedade colombiana vem atravessando, todo o drama que o país vem vivendo ao longo de décadas com os constantes conflitos entre guerrilheiros e o governo, contudo, é um acontecimento por demais doloroso que ficará marcado na história do país. Em suma, não tem como ser ignorado, pois a proporção de tal acontecimento pode desencadear movimentos com desdobramentos em aspectos conjunturais e até nas estruturas mais profundas da organização social desse país localizado bem próximo do Brasil.

A título de hipótese: Essa onda de violência poderia, por exemplo, fazer com que o governo revisse a sua política em 
relação às FARC e repensasse a questão agrária no país, marcada pela concentração de terra, herdada da estrutura fundiária constituída no período colonial ou desse uma guinada de cento e oitenta graus e atendesse os interesses dos grandes fazendeiros e desencadeasse uma repressão sem precedentes sobre os guerrilheiros para acabar com as FARC. Note que há um campo vasto de possibilidades sobre essa realidade social e os alunos, quando forem pensar outras realidades devem ter a mesma percepção, ou seja, devem compreender que os agentes históricos, não importam a temporalidade, também estavam numa situação que precisaram jogar com as possibilidades, pois a trajetória não estava dada a priori.

Neste mesmo dia o Jornal do Brasil estampou a seguinte manchete numa das matérias: "Homicídios são epidemia, diz secretário". A notícia se refere ao relatório divulgado pela Unesco sobre os índices de violência no país na última década. Neste estudo se constatou que as taxas de homicídio aumentaram em 17 Estados brasileiros. Paulo Sérgio Pinheiro, Secretário de Estado dos Direitos Humanos, qualificou os assassinatos de jovens no país como uma "epidemia", afirmando também que o país tem uma política "suicida" para a juventude. Para essa autoridade governamental, "o relatório é um tiro no pé do Brasil". Chama a atenção nesta notícia, o fato de que o jovem morador do Rio de Janeiro e de Pernambuco, em 1998, corria mais riscos de vida que a juventude da Colômbia, país que vive uma guerrilha e é recordista mundial de violência.

A notícia não se refere a um acontecimento breve, mas a questão da violência no Brasil nos últimos dez anos. $\mathrm{O}$ grande número de homicídios na sociedade brasileira na última década e que, por sinal, tem sido percebido por quase toda a sociedade, é um fato histórico. Seguindo a linha de raciocínio de Braudel, poderíamos dizer que as pessoas estão com a percepção de que 
estão passando por um período em que o nível de violência no país chegou a um patamar que se diferencia muito das décadas anteriores. Neste caso, o tempo histórico contido nesta fonte é o da conjuntura, pois os grupos sociais encontram-se em meio a uma situação completamente diferente de outros períodos que viveram. $\mathrm{O}$ importante aqui é que os alunos compreendam que a fonte traz a informação de que estamos diante de um ciclo que já dura dez anos.

No caderno de imóveis do dia 04/05/2002, o Jornal do Brasil faz uma reportagem de página inteira com a seguinte manchete: "Imóveis adequados aos tempos modernos". Segundo a jornalista responsável pela matéria, houve uma mudança no comportamento da sociedade que está afetando o mercado. imobiliário. Segundo ela, atualmente "as famílias estão menores, o tempo está cada vez mais curto e o brasileiro está com menor poder de compra, tendo que contar sempre com financiamentos". Ao entrevistar o presidente do Conselho Regional de Corretores de Imóveis do Rio de Janeiro, o mesmo argumenta que é "fácil ver as diferenças entre um imóvel antigo e um novo. A questão é que casas e apartamentos antigos, onde salas e cozinhas são grandes e geralmente contam com muitos quartos, estão bem mais difíceis de serem vendidos hoje [...] A tendência do mercado, frente à nova realidade social, está para os apartamentos de quarto e sala e dois quartos, no máximo".

Segundo a reportagem, está havendo uma mudança no comportamento do brasileiro, na qual as famílias estão menores, com isso refletindo nas formas de habitação. Logicamente que a referência é em relação a segmentos da classe média que possuem um poder aquisitivo que permite a eles adquirir um imóvel. Não traz a reportagem qualquer indicação sobre outros segmentos sociais, como por exemplo, as classes populares. Mas isto não impede que a questão do fato e do tempo histórico 
seja tratada nessa reportagem. Contudo, queremos chamar a atenção de que as fontes, sejam elas quais forem, sempre trazem uma informação parcial da realidade.

Note que há a indicação de que estão ocorrendo mudanças significativas na sociedade brasileira nas últimas décadas. A existência de famílias menores, devido as dificuldades econômicas, a vida agitada das grandes cidades e o ritmo alucinante em tempo de globalização, parece ser o novo perfil da família brasileira de classe média, portanto, muito diferente do modelo existente em outros momentos históricos da sociedade brasileira. Podemos, portanto, definir como fato histórico nesta reportagem este novo padrão de família brasileira de classe média. Quando tratamos de tempo histórico, a própria reportagem está mencionando uma tendência que vem acontecendo nos últimos tempos, neste caso, está tratando de uma conjuntura onde alterações profundas estão ocorrendo.

Como o próprio Braudel salienta, as conjunturas têm ligações com as estruturas. Se nesta reportagem há referência a um outro perfil de família que vem se constituindo nas últimas décadas, não poderíamos deixar de fazer uma relação com o outro modelo familiar presente ao longo de séculos de história do país. Portanto, há uma mudança conjuntural que está afetando um aspecto estrutural que é o antigo modelo de família brasileira. Aqui caberia até indagar se essa estrutura familiar, esse fato histórico de longa duração, ficará intocada diante das agitações e turbulências dos últimos tempos.

Como se pode ver o jornal impresso representa um material riquíssimo para se trabalhar em sala de aula. Mais ainda, não precisou de um longo trabalho de pesquisa para selecionar as notícias, pois as matérias foram coletadas num único dia.

Para finalizar, gostaríamos de salientar que consideramos que se cada vez mais houver uma preocupação de estabelecer 
uma metodologia no ensino, sedimentando os fundamentos da disciplina, daremos passos significativos para que a História quebre os preconceitos e passe a ocupar um importante papel na formação de cidadãos.

\section{Bibliografia não citada}

AHMAD, Aijaz. Cultura, nacionalismo e o papel dos intelectuais. In: WOOD, Ellen M. ; FOSTER, John B (Orgs.) Em defesa da história: marxismo e pós-modernismo. Rio de Janeiro: Jorge Zahar, 1999, p. 59-73.

BURKE, Peter (Org.) A escrita da história: novas perspectivas. São Paulo: UNESP, 1992.

DARNTON, Robert. Jornalismo: toda notícia que couber, a gente publica. In: O beijo de Lamourete. São Paulo: Cia das Letras, 1990.

DAVIES, Nicholas. Para além dos conteúdos no ensino de história. Niterói: EDUFF, 2000.

FARIA, Maria Alice. O jomal na sala de aula. São Paulo: Contexto, 1992.

GOMES, Angela Maria de Castro. Notas sobre uma experiência de trabalho com fontes: arquivos privados e jornais. RBH, v. 1, n. 2, set.1981. São Paulo.

HOBSBAWM, Eric. Não basta a história da identidade. In: Sobre história: ensaios. São Paulo: Cia das Letras. 1998. p. 281-292.

LE GOFF, Jacques. A nova história. São Paulo: Martins Fontes, 1993.

LE GOFF, Jacques. As idades médias de Michelet. In: Para um novo conceito de Idade Média: tempo, trabalho e cultura no ocidente. Lisboa: Editorial Estampa, 1980, p.19-42.

MEERA, Nada. Contra a destruição/desconstrução da ciência: histórias cautelares do terceiro mundo. In: WOOD, Ellen M. ; FOSTER, John B (Orgs.). Op. Cit. p. 84-106.

OSAKABE, Haquira. Argumentação e discurso político. São Paulo: Kairós, 1979. 
ROUANET, Sérgio Paulo. As razões do Iluminismo. São Paulo: Cia das Letras, 1987.

SCHORSKE, Carl E. Pensando com a história: indagações na passagem para o modernismo. São Paulo: Cia das Letras, 2000.

ZICMAN, Renée. História através da imprensa: algumas considerações metodológicas. Projeto História n. 04, jun. 1985. São Paulo: PUC-SP.

\section{ABSTRACT:}

In this paper, we suggest a way of working with press, in order to transmit the concepts of historical fact and time. We take in account Braudel's idea of short/long term duration. We work with practical examples, based on press reports, trying to show how this can be pedagogically used at first and second grade schools.

KEY-WORDS:

historical facts, historical time, context, social structure. 